Document downloaded from:

http://hdl.handle.net/10251/86458

This paper must be cited as:

Tukappa, A.; Ultimo, A.; De La Torre Paredes, C.; Pardo Vicente, MT.; Sancenón Galarza, F.; Martínez-Máñez, R. (2016). Polyglutamic Acid-Gated Mesoporous Silica Nanoparticles for Enzyme-Controlled Drug Delivery. Langmuir. 32(33):8507-8515. doi:10.1021/acs.langmuir.6b01715.

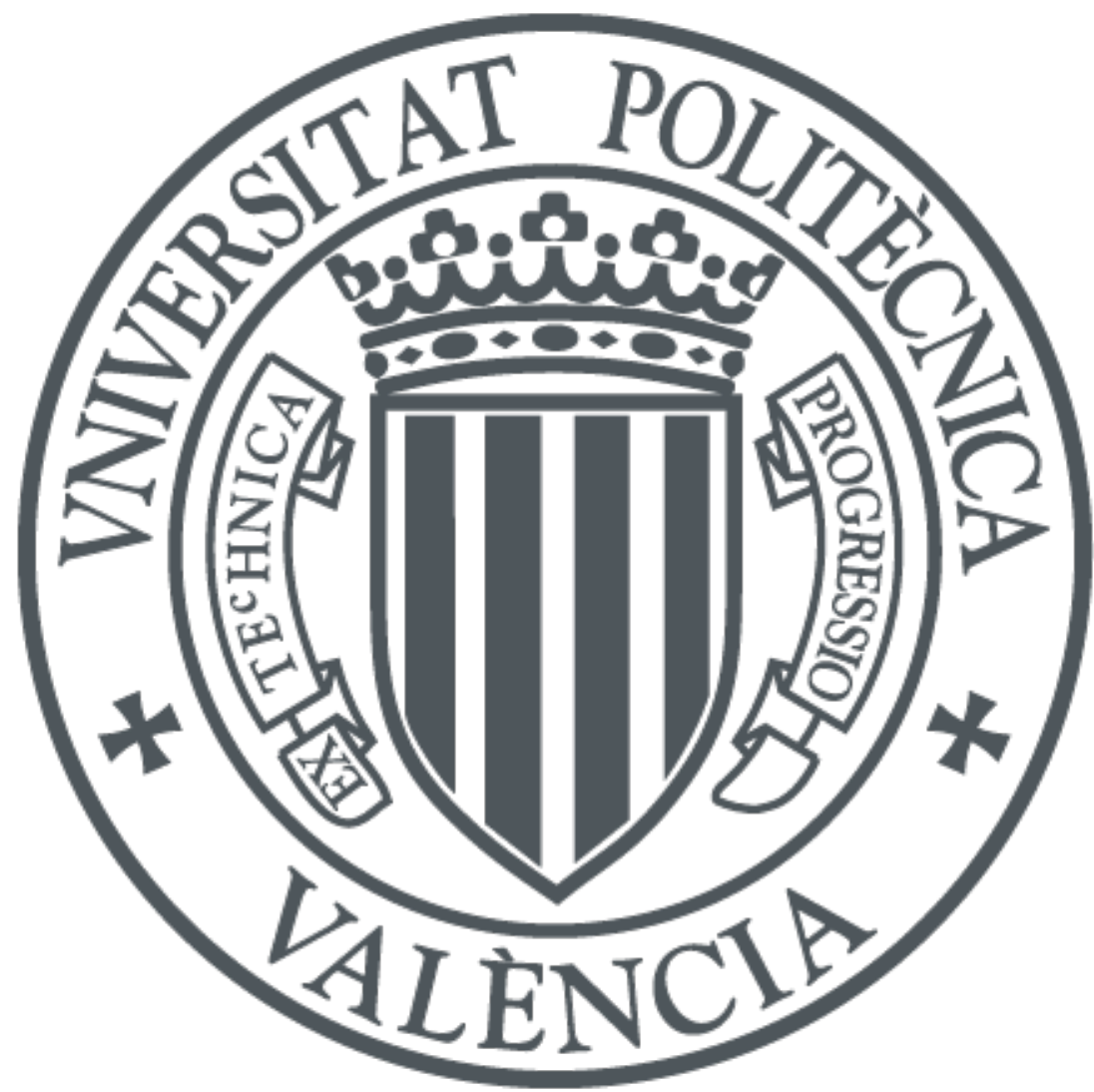

The final publication is available at

http://dx.doi.org/10.1021/acs.langmuir.6b01715

Copyright American Chemical Society

Additional Information

This document is the Accepted Manuscript version of a Published Work that appeared in final form in

Langmuir, copyright (c) American Chemical Society after peer review and technical editing by the publisher.

To access the final edited and published work see http://dx.doi.org/10.1021/acs.langmuir.6b01715. 


\section{Polyglutamic acid-gated mesoporous silica nanoparticles for enzyme-controlled drug delivery}

Asha Tukappa, ${ }^{\#,+, \neq}$ Amelia Ultimo, ${ }^{\#, t, \S}$ Cristina de la Torre, ${ }^{\dagger, \S}$ Teresa Pardo, ${ }^{\dagger, \S}$ Félix Sancenón, ${ }^{\dagger, \S}$ Ramón Martínez-Máñez ${ }^{*,+,}$

${ }^{\dagger}$ Dr. A. Tukappa, A. Ultimo, C. de la Torre, Dr. T. Pardo, Dr. F. Sancenón, Prof. R. MartínezMáñez

Instituto Interuniversitario de Investigación de Reconocimiento Molecular y Desarrollo Tecnológico (IDM). Universitat Politècnica de València, Universitat de València.

Camino de Vera s/n 46022, Valencia, Spain

${ }^{\ddagger}$ A. Tukappa

Department of Biotechnology, Gulbarga University

Gulbarga 585106, Karnataka, India

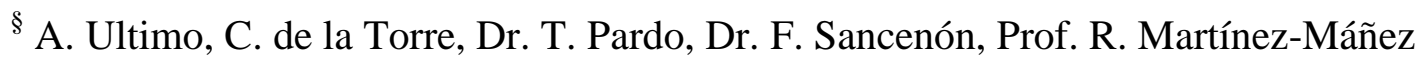

CIBER de Bioingeniería, Biomateriales y Nanomedicina (CIBER-BBN)

Mesoporous silica nanoparticles - Polyglutamic acid - Doxorubicin - Controlled drug release

ABSTRACT: Mesoporous silica nanoparticles (MSNs) are highly attractive supports for the design of controlled delivery systems able to act as containers for the encapsulation of therapeutic agents overcoming common issues such as poor water solubility and poor stability of some drugs and also enhancing their bioavailability. In this context, we describe herein the development of polyglutamic acid (PGA)-capped MSNs able to selectively deliver rhodamine B 
and doxorubicin. PGA-capped MSNs remained closed in an aqueous environment yet are able to deliver the cargo in the presence of pronase due to the hydrolysis of the peptide bonds in PGA. The solids prepared released less than $20 \%$ of the cargo in one day, whereas they were able to reach $90 \%$ of the maximum release of the entrapped guest in ca. $5 \mathrm{~h}$ in the presence of pronase. Studies of the PGA-capped nanoparticles with SK-BR-3 breast cancer cells was also tested. Rhodamine-loaded nanoparticles were not toxic, while doxorubicin-loaded nanoparticles were able to kill efficiently more than $90 \%$ of cancer cells at a concentration of $100 \mu \mathrm{g} / \mathrm{ml}$.

\section{Introduction}

Despite notable improvements in recent years in the development of new therapeutic approaches, due to a better knowledge about drugs physicochemical properties and the mechanisms of their cellular uptake, many of the antitumor drugs commonly used in chemotherapy still present significant adverse effects and, often, a poor efficacy. ${ }^{1-5}$ These usual issues for drugs in oncologic treatments normally resulted in lack of specificity. Moreover some drugs show poor solubility, stability or are rapidly eliminated. ${ }^{6-8}$ In this context nanomedicine attempts to offer a broad variety of tools aimed to improve conventional therapeutic and diagnostic strategies, being a landmark purpose the development of more effective and safer treatments, reducing toxicity of drugs to non-target organs. ${ }^{9-13}$

In this scenario a large variety of drug nanocarriers with different size, structure and surface features, such as liposomes, ${ }^{14-16}$ polymeric nanoparticles ${ }^{17-19}$ or inorganic nanoparticles has been developed over the last few decades. ${ }^{20,21}$ Among them mesoporous silica nanoparticles (MSNs) have gained great attention due to their unique features such as stability, 
biocompatibility, large load capacity and the possibility of easy functionalizing their surface to obtain targeting and drug release-controlling nanodevices. ${ }^{22,23}$ In particular, the MCM-41 material with an hexagonal arrangement of cylindrical mesopores has been extensively studied, since its first use as a drug nanocarrier in $2001 .{ }^{24}$ Since then, many MCM-41-based nanoparticles have been developed, most of them including different molecules attached on MSNs surface acting as specific stimuli-responsive gates, thus allowing "zero premature release” and delivery only upon application of a specific stimulus. ${ }^{25,26,27}$ These concepts have allowed researchers to design on-command delivery carriers that can be triggered by stimuli such as changes in $\mathrm{pH},{ }^{28-37}$ light, ${ }^{38-45}$ temperature ${ }^{46-50}$ or ultrasound, ${ }^{51,52}$ and the presence of given enzymes ${ }^{53,54}$ or of complementary oligonucleotides..$^{55-58}$

In particular, the enzymatic degradation of gatekeepers in MSNs represents an interesting way to achieve controlled release of drugs in target cells. In fact, the use of tailor-made capping derivatives and enzymes is envisioned to have a large potential in providing selectivity in advanced gated devices for delivery of drugs and biomolecules at-will in biological environments. In particular, when combined with the unique properties of MSNs, enzymeresponsive systems can be designed to perform target functions with high specificity which is controlled by the triggering enzyme. Moreover, the use of enzymes for selective release applications opens up a wide range of new perspectives in the design of bio-compatible release systems. In fact, and despite some reported enzyme-responsive nanomaterials for programmed drug release, examples of enzyme-induced delivery using capped MSNs are still relatively limited. In this subfield of gated nanochemistry examples that use esterases, ${ }^{59-61}$ glycosidases, ${ }^{62-64}$ peptidases, ${ }^{65-68}$ reductases, ${ }^{69,70}$ and DNases ${ }^{71,72}$ have been reported. In relation to caps, small molecules, certain oligomers, polymers, peptides and DNA sequences able to be hydrolysed in 
the presence of target enzymes have been used. ${ }^{25}$ In relation to polymers, we have focused our attention to poly-L-glutamic acid (PGA) as a suitable polymer to be used as gatekeeper in gated mesoporous materials due to its firm stability in plasma and easy degradation by lysosomal enzyme cathepsin B. ${ }^{73,74}$ In addition, PGA is a non-toxic and non-immunogenic molecule that for instance has already been employed in a phase III trial polymer-anticancer drug conjugate, Opaxio, consisting of paclitaxel conjugated to glutamic acid residues applied to ovarian or fallopian tube cancer treatment. ${ }^{75}$ In fact the use of PGA nanoparticles as carriers to encapsulate drugs has been extensively explored. ${ }^{76}$ However, as far as we know, the combined use of PGA and MSNs is rare. Moreover MSNs are easy to poly-functionalize. For instance, this polyfunctionalization allows the incorporation of gating entities (that could control the release of the cargo at will upon application of external stimuli), targeting ligands or dyes/fluorophores/metallic nanoparticles for diagnostic purposes. Moreover, nanoporous silica scaffolds can be loaded with a number of different cargoes.

In this context, and taking into account our interest in the development of gated MSNs for mass transport and controlled delivery, ${ }^{25,77}$ it was in our aim to design a PGA gated material, based on MSNs, as a simple to prepare and stable delivery systems of cytotoxic agents. In particular we described herein the preparation of two hybrid mesoporous silica nanoparticles loaded with rhodamine B (S1) or doxorubicin (S2) and functionalised with PGA. Cargo delivery studies in the absence and presence of pronase were carried out. Moreover the use of the nanoparticles as suitable systems to deliver the cargo in breast cancer cells is demonstrated.

\section{Experimental}


Reagents. The chemicals tetraethylorthosilicate (TEOS), n-cetyltrimethylammonium bromide (CTAB), sodium hydroxide ( $\mathrm{NaOH}$ ), (3-aminopropyl)triethoxysilane (APTES), poly-L-glutamic acid (PGA) sodium salt (MW 6300), 1-ethyl-3-(3-dimethylaminopropyl)carbodiimide (EDC), D6046 DMEM medium and pronase from S. griseus were provided by Aldrich. The cell proliferation reagent WST-1 was obtained from Roche Applied Science and SK-BR-3 human breast carcinoma cells from American Type Culture Collection. Doxorubicin hydrochloride was provided by Sequoia Research Products, Ltd. All products were used as received.

General Techniques. Powder X-ray measurements were performed on a Seifert 3000TT diffractometer using $\mathrm{CuK \alpha}$ radiation. Thermogravimetric analyses were carried out on a TGA/SDTA 851e Mettler Toledo balance, using an oxidant atmosphere (air, $80 \mathrm{~mL} / \mathrm{min}$ ) with a heating program consisting of a heating ramp of $10^{\circ} \mathrm{C}$ per minute from 393 to $1273 \mathrm{~K}$ and an isothermal heating step at this temperature for $30 \mathrm{~min}$. Elemental analysis was performed in a CE Instrument EA-1110 CHN Elemental Analyzer. Transmission electron microscopy (TEM) images were obtained with a $100 \mathrm{kV}$ Philips CM10 microscope. $\mathrm{N}_{2}$ adsorption-desorption isotherms were recorded with a Micromeritics ASAP2010 automated sorption analyzer. The samples were degassed at $120^{\circ} \mathrm{C}$ in vacuum overnight. The specific surface areas were calculated from the adsorption data in the low pressure range using the Brunauer-Emmett-Teller (BET) model. Pore size was determined following the Barrett-Joyner-Halenda(BJH) method. Fluorescence measurements were carried out in a JASCO FP-8500 Spectrophotometer. Confocal microscopy imaging was performed using a Zeiss LSM 710 microscope. Cell viability measurements were carried out with a Multiskan Microplate Photometer by Thermo Scientific.

\section{Synthesis of MCM-41 mesoporous silica nanoparticles. The MCM-41 mesoporous} nanoparticles were synthesized using the following procedure: n-cetyltrimethylammonium 
bromide (CTAB, $1.00 \mathrm{~g}, 2.74 \mathrm{mmol}$ ) was first dissolved in $480 \mathrm{~mL}$ of deionized water. Then $\mathrm{NaOH}\left(3.5 \mathrm{~mL}, 2.00 \mathrm{~mol} \mathrm{~L}^{-1}\right)$ in deionized water was added to the CTAB solution, followed by adjusting the solution temperature to $80^{\circ} \mathrm{C}$. TEOS $\left(5.00 \mathrm{~mL}, 2.57 \times 10^{-2} \mathrm{~mol}\right)$ was then added dropwise to the surfactant solution. The mixture was allowed to stir for $2 \mathrm{~h}$ to give a white precipitate. Finally the solid product was centrifuged, washed with deionized water and dried at $60^{\circ} \mathrm{C}$. To prepare the final porous material (calcined MCM-41), the as-synthesized solid was calcined at $550^{\circ} \mathrm{C}$ using an oxidant atmosphere for $5 \mathrm{~h}$ in order to remove the template phase.

Synthesis of solid S1. $400 \mathrm{mg}$ of calcined MCM-14 and $200 \mathrm{mg}$ of rhodamine B dye were suspended in $17.5 \mathrm{ml}$ of anhydrous acetonitrile. The mixture was stirred for $24 \mathrm{~h}$ at room temperature, in order to achieve the maximum loading of dye in the mesopores, and then was filtered and dried under vacuum. $200 \mathrm{mg}$ of the loaded solid were resuspended in $8.5 \mathrm{ml}$ of acetonitrile in presence of APTES (1.875 ml) and of an excess of rhodamine B (60 mg). The suspension was stirred for $5.5 \mathrm{~h}$ at room temperature. The resulting solid was centrifuged and washed with acetonitrile to remove the dye molecules present outside the pores and then was dried under vacuum. Finally $100 \mathrm{mg}$ of the solid and $354 \mathrm{mg}$ of PGA (0.03 mol) were suspended in $16 \mathrm{ml}$ of $0.1 \mathrm{M}$ PBS in presence of an excess of rhodamine B and EDC (191.7 mg, $0.5 \mathrm{mmol}$ ). The mixture was stirred at room temperature for $24 \mathrm{~h}$ and the final S1 material was obtained, washed with abundant water and dried under vacuum.

Synthesis of solid S2. Solid S2 was prepared following the same procedure described for S1 but, in this case, the MCM-41 material was loaded with doxorubicin. $200 \mathrm{mg}$ of calcined MCM-14 and $40 \mathrm{mg}$ of doxorubicin were suspended in $1.6 \mathrm{ml}$ of deionised water and stirred for $24 \mathrm{~h}$ at room temperature. Then the mixture was filtered and dried under vacuum. The doxorubicin 
loaded solid (200 mg) was then resuspended in $8.5 \mathrm{ml}$ of acetonitrile in presence of an excess of doxorubicin and APTES $(1.88 \mathrm{ml})$. The suspension was stirred for $5.5 \mathrm{~h}$ at room temperature. The obtained solid was isolated by centrifugation, washed with acetonitrile and dried under vacuum. Afterward, this functionalized solid (100 mg) was suspended in $0.1 \mathrm{M}$ PBS with 354 mg of PGA in the presence of an excess of doxorubicin and EDC (191.7 mg, $0.5 \mathrm{mmol})$. The mixture was stirred at room temperature for $24 \mathrm{~h}$ and finally the $\mathbf{S 2}$ solid was isolated by centrifugation and washed with abundant water followed by drying under vacuum.

Cargo Release Studies. In a typical experiment, $1 \mathrm{mg}$ of $\mathbf{S 1}$ or $\mathbf{S 2}$ were suspended in $1 \mathrm{~mL}$ of distilled water at $\mathrm{pH} 8.0$ and sonicated. Then, each suspension was divided into two aliquots of $500 \mu \mathrm{L}$ and $2.5 \mathrm{~mL}$ of distilled water at $\mathrm{pH} 8.0$ or $1 \mathrm{~mL}$ of pronase solution $(0.12 \mathrm{mg} / \mathrm{ml}$ in distilled water at $\mathrm{pH}$ 8.0) was added. Dye or drug delivery was monitored through the emission band of rhodamine $B$ or doxorubicin centred at $610 \mathrm{~nm}\left(\lambda_{\text {exc }}=453 \mathrm{~nm}\right)$ or $557 \mathrm{~nm}\left(\lambda_{\text {exc }}=480\right.$ $\mathrm{nm})$, respectively.

Cell Culture Conditions. SK-BR-3 human breast cancer cells were cultured at $37^{\circ} \mathrm{C}$ in DMEM medium containing $1000 \mathrm{mg} / \mathrm{L}$ glucose, phenol red, 10\% fetal calf serum and $2 \mathrm{mM}$ glutamine.

Confocal Microscopy Imaging. SK-BR3 cells were seeded on $24 \mathrm{~mm}$ glass coverslips in 6-well plates in triplicate at a seeding density of $8 \times 10^{5}$ cells/well. After $48 \mathrm{~h}$, cells were treated with $\mathbf{S 1}$ or $\mathbf{S} 2$ at a final concentration of $50 \mu \mathrm{g} / \mathrm{mL}$ during $48 \mathrm{~h}$ more.

WST-1 Cells Viability Assay. Quantitation of cell viability rates was determined using Cell Proliferation Reagent WST-1 following supplier's instructions. Cells were cultured in sterile 96- 
well microtiter plates $\left(25 \times 10^{3}\right.$ cells/well $)$ in triplicate and were allowed to settle for $48 \mathrm{~h}$. Then solid S1 or S2 were added at the final concentration of 100, 50, 25, 12.5 and $6.25 \mu \mathrm{g} / \mathrm{mL}$ during 48h. Then, DMEM medium was removed and replaced with PBS with $1000 \mathrm{mg} / \mathrm{L}$ glucose to avoid phenol red interference with the absorbance reading, WST-1 was added and the plates were incubated for $1 \mathrm{~h}$ at $37^{\circ} \mathrm{C}$. Finally, the absorbance at $490 \mathrm{~nm}$ was measured.

\section{Results and Discussion}

\section{Design and synthesis of gated materials}

The delivery system we have designed is depicted in Scheme 1. PGA molecules are expected to block the mesopores and to prevent cargo release until cellular uptake of the nanoparticles and their consequent endosomal/lysosomal internalization. We speculated that lysosomal proteolytic enzymes would degrade PGA by cleaving the peptide bonds, thus inducing the uncapping of the pores and the release of the cargo.

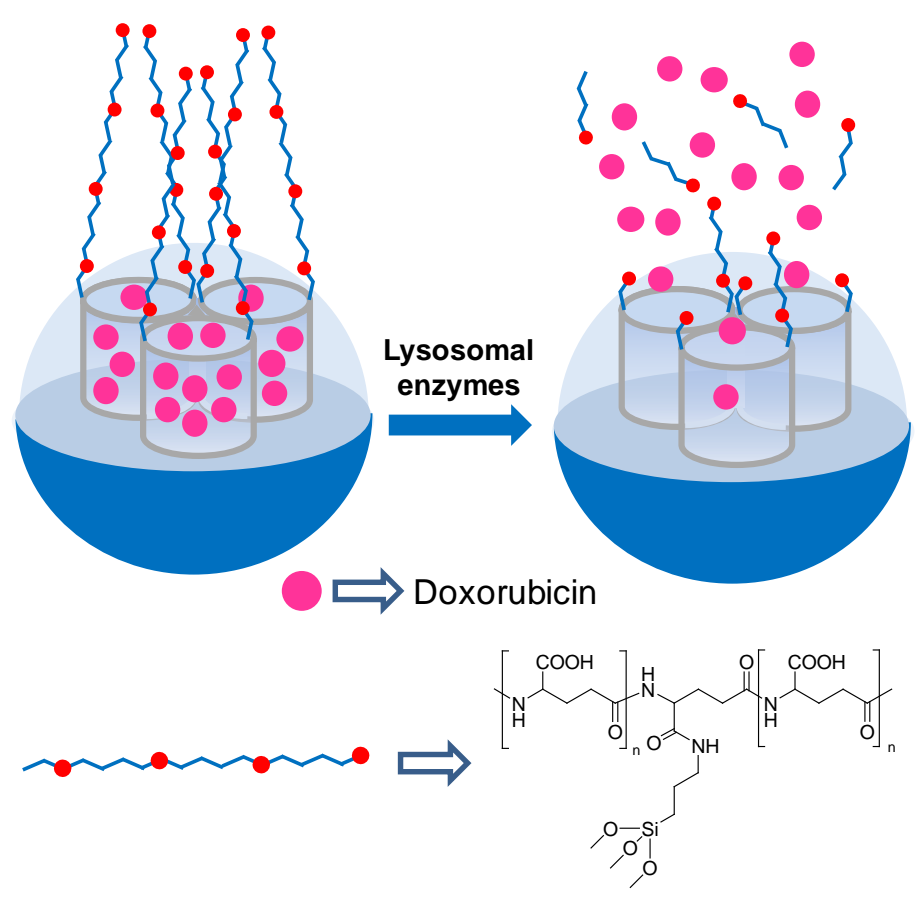


Scheme 1. MSNs capped with PGA. Cargo delivery is selectively observed in the presence of lysosomal enzymes.

Mesoporous silica MCM-41 nanoparticles are suitable scaffolds for the development of hybrid materials for controlled delivery applications due to their remarkable properties as the presence of homogeneous mesopores of ca. 2-3 nm, large loading ability and easyfunctionalizable surface for the anchoring of (bio)molecules able to act as molecular caps. In the

present work, MSNs were synthesized following a well-known procedure, using $n$ cetyltrimethylammonium bromide (CTAB) as a structure directing agent and tetraethyl orthosilicate (TEOS) as hydrolyzable precursor. After the synthesis the surfactant was removed by calcination in air at high temperature to finally obtain mesoporous inorganic nanoparticles, which were then loaded with rhodamine B (for solid S1) or doxorubicin (for solid S2). The loaded solids were functionalized with APTES and capped with PGA (through an amidation reaction using EDC as coupling agent).

\section{Materials Characterization}

Once obtained, nanoparticles S1 and S2 were characterized by standard procedures. Figure 1 shows the powder XRD spectrum of MCM-41 as-synthesized, the calcined MCM-41 and S1 material. MCM-41 as-synthesized spectrum (Figure 1a) shows the typical low angle reflections of a hexagonal ordered array which can be indexed as (100), (110), (200) and (210) Bragg peaks. In case of calcined MCM-41 (Figure 1b), a significant displacement of the (100) reflection and broadening of (110) and (200) peaks was observed, which is related with a cell contraction of ca. 6-8 $\AA$ due to the condensation of the silanol groups as consequence of the calcination step. Figure 1c shows the XRD pattern for solid S1. In this case the reflections (110) 
and (200) are not observed most likely because of a loss of contrast due to the filling of the pores with rhodamine B. However, the clear presence of the (100) reflection indicates that the process of pore loading and further functionalization with PGA did not transform the mesoporous structure of the nanoparticles.

The mesoporous structure of the final functionalized solid S1 was also confirmed by transmission electron microscopy (TEM). Figure 2 shows the spherical morphology of the obtained materials and the typical channels of the MCM-41 matrix are visualized as a pseudohexagonal array of pore voids or as alternate black and white strips. As it can be seen, the prepared MSNs have a diameter of ca. $100 \mathrm{~nm}$ (Figure 2a) and the final solid S1 keeps the initial morphology of the MCM-41 matrix despite the loading and functionalization processes (Figure 2c).

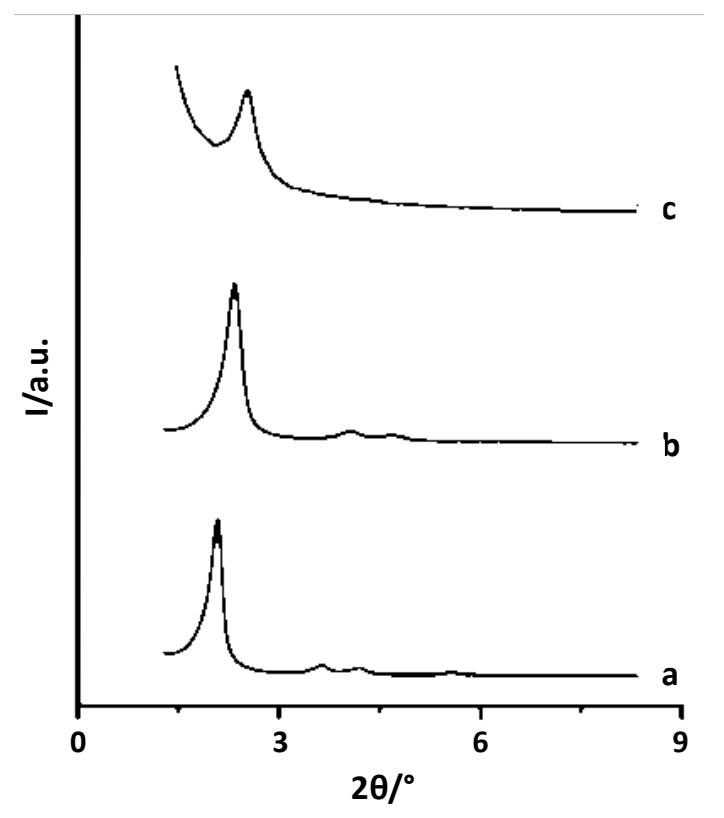

Figure 1. X-Ray diffraction pattern of (a) MCM-41 as synthesized, (b) calcined MCM-41 and (c) S1 solid containing rhodamine B. 


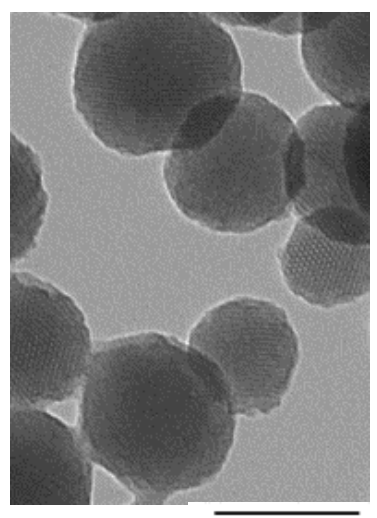

a)

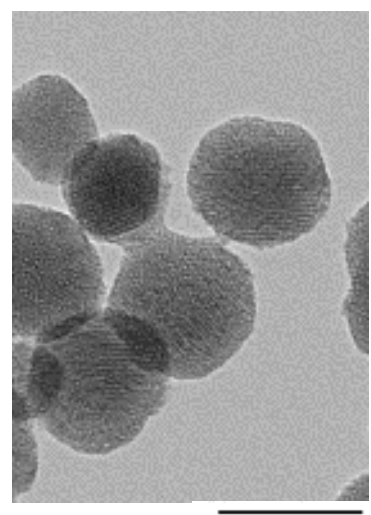

$100 \mathrm{~nm} \quad$ c)

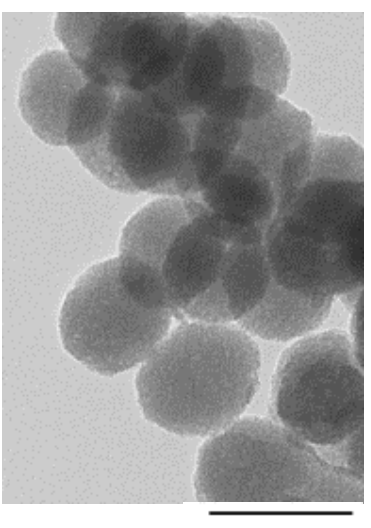

$100 \mathrm{~nm}$

Figure 2. TEM images of (a) MCM-41 as synthesized, (b) calcined MCM-41 and (c) solid S1.

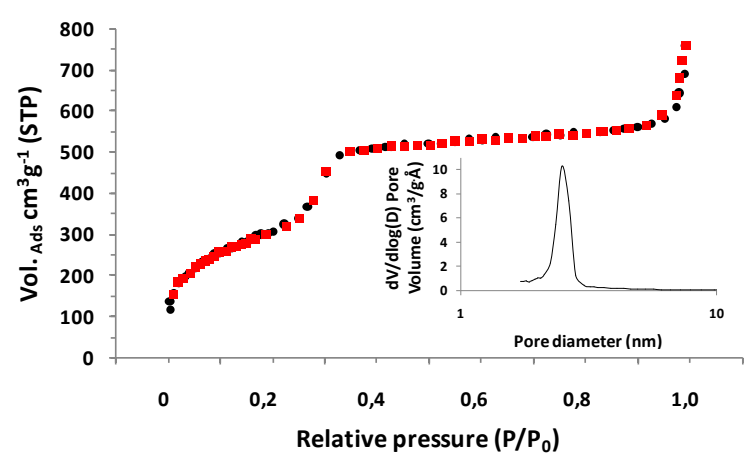

a)

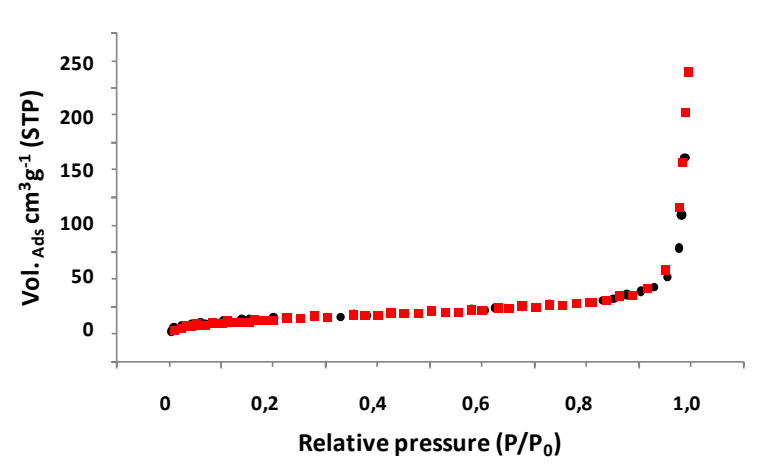

b)

Figure 3. Nitrogen adsorption-desorption isotherms for (a) calcined MCM-41 (insets: pore-size distribution) and (b) solid S1.

The $\mathrm{N}_{2}$ adsorption- desorption isotherm of calcined MCM-41 (Figure 3a) shows an adsorption step at medium $P / P_{0}$ values (0.2-0.4), typical of this family of mesoporous solids, which corresponds to nitrogen condensation inside the mesoporous by capillarity. Moreover, there is an absence of a hysteresis loop in this interval. This together with the narrow BJH pore distribution suggested the presence of uniform cylindrical mesopores. A pore diameter of $2.5 \mathrm{~nm}$ 
and pore volume of $0.91 \mathrm{~cm}^{3} \mathrm{~g}^{-1}$, calculated by using BJH model on the adsorption branch of the isotherm, were observed. Application of the BET model resulted in a total specific surface of $1081.6 \mathrm{~m}^{2} \mathrm{~g}^{-1}$ for the starting calcined MSNs. In addition to this first adsorption step, a second feature appears in the isotherm at a higher relative pressure $\left(P / P_{0}>0.8\right)$. This adsorption corresponds to the filling of the large voids among the particles and therefore must be considered as textural-like porosity. A pore diameter of $47.0 \mathrm{~nm}$ and pore volume of $0.24 \mathrm{~cm}^{3} \mathrm{~g}^{-1}$ was calculated in this interval. In contrast, adsorption-desorption isotherms for S1 and S2 are typical of MSNs systems with filled mesopores (Figure 3b) and a considerable reduction of specific surface area was observed. In particular BET areas of 56.5 and $39.9 \mathrm{~m}^{2} \mathrm{~g}^{-1}$ were calculated for $\mathbf{S 1}$ and S2, respectively (see Table 1).

Table 1. BET Specific surface values, pore volumes and pore sizes calculated from the $\mathrm{N}_{2}$ adsorption-desorption isotherms for selected materials.

\begin{tabular}{cccc}
\hline & $\begin{array}{c}\text { S } \\
\left(\mathbf{m}^{2} \mathbf{g}^{-1}\right)\end{array}$ & $\begin{array}{c}\text { Pore volume } \\
\left(\mathbf{c m}^{\mathbf{3}} \mathbf{g}^{-\mathbf{1}}\right)\end{array}$ & $\begin{array}{c}\text { Pore size } \\
\mathbf{( n m )}\end{array}$ \\
\hline Calcined MCM-41 & 1081.6 & 0.91 & 2.54 \\
S1 & 56.5 & - & - \\
S2 & 39.9 & - & - \\
\hline
\end{tabular}

The content of rhodamine B/doxorubicin and grafted PGA in solids S1 and S2 was determined by elemental and thermogravimetric analysis and by UV-measurements. Contents of organic components for solids $\mathbf{S} \mathbf{1}$ and $\mathbf{S} 2$ are listed in Table 2. 
Table 2. Content (mg/g of solid) of the different loading and functionalization moieties in S1 and S2.

\begin{tabular}{cccc}
\hline & $\begin{array}{c}\text { Rhodamine B } \\
\text { (mg/g solid) }\end{array}$ & $\begin{array}{c}\text { Doxorubicin } \\
\text { (mg/g solid) }\end{array}$ & PGA \\
(mg/g solid)
\end{tabular}

\section{Delivery Studies}

As stated above, it was our aim the design of release MSNs triggered by the presence of proteases in cells. In a first step delivery assays in aqueous solution were carried out using S1 and S2. For instance, in a typical experiment S1 nanoparticles were suspended in water at pH 8.0 both, in the absence and presence of pronase. At certain scheduled times, aliquots were separated, centrifuged and the delivery of rhodamine B dye from the pore voids was determined through monitoring the emission band of rhodamine $B$ at $610 \mathrm{~nm}\left(\lambda_{\mathrm{ex}}=453 \mathrm{~nm}\right)$ in the aqueous phase (see Figure 4). Solid S1 displayed a poor release profile (curve a) in water, whereas it delivered the dye in the presence of pronase. In particular, $\mathbf{S 1}$ nanoparticles were able to release less than $20 \%$ of the cargo at least for $25 \mathrm{~h}$ in the absence of the enzyme, whereas cargo delivery was observed achieving $90 \%$ of the maximum release of the entrapped guest in ca. $5 \mathrm{~h}$ in the presence of pronase. These results indicate that anchored PGA chains form a barrier that inhibits release of rhodamine $\mathrm{B}$ efficiently. However, when pronase is present, the peptide bonds in the anchored PGA are hydrolyzed resulting in the release of the entrapped cargo.

Using a similar experimental protocol, cargo release studies from solid S2, containing the drug doxorubicin, in the absence and presence of pronase were carried out. In this case cargo 
delivery was monitored through the fluorescence band of doxorubicin at $557 \mathrm{~nm}\left(\lambda_{\text {exc }}=480 \mathrm{~nm}\right)$. The obtained experimental results are also shown in Figure 4. As for S1, a poor cargo release was found in the absence of pronase, whereas a clear doxorubicin delivery was observed in the presence of this enzyme.

a)

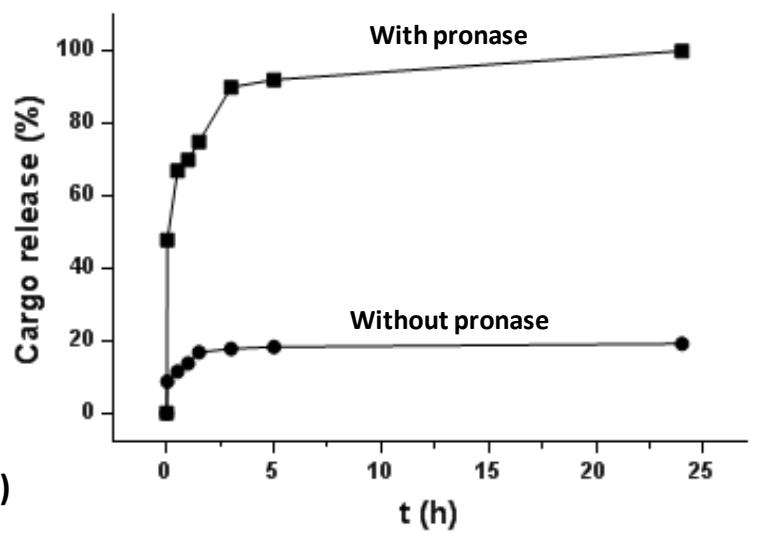

b)

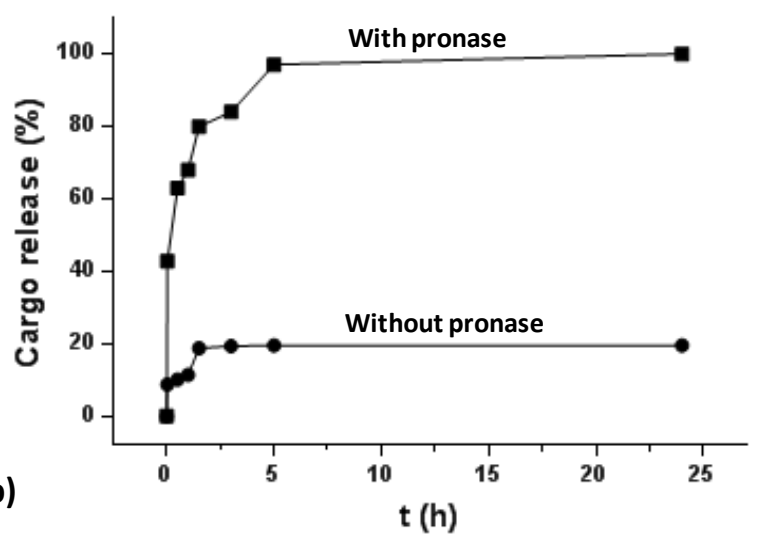

Figure 4. a) Kinetics of release of rhodamine B from solid S1 in absence and presence of pronase. b) Kinetics of release of doxorubicin from solid S2 in absence and presence of pronase.

\section{Confocal Microscopy Imaging and Viability Assays}

After the in vitro characterization, the gated MSNs S1 and S2 were also used for further ex vivo assays. For these experiments SK-BR-3 breast cancer cells overexpressing the human epidermal growth factor receptor2 (HER2) were used. ${ }^{78}$ HER2 is overexpressed in $20 \%$ of invasive breast cancers, that results in more aggressive disease with a worse prognosis. In the last decades, the development of immunotherapeutic strategies based on a recombinant humanized anti-HER2 monoclonal antibody, Trastuzumab, has allowed the improvement of the disease-free and overall survival in both primary and metastatic breast HER2 enriched tumors. Nevertheless, 
this approach is not always effective, indicating the existence of resistant tumours and underlying the urgent need to develop new therapies. ${ }^{79,80}$

To study the penetrability of the developed nanodevices, cells were seeded in 6-well culture plates at a density of 150000 cells per well and allowed to adhere for 24h. After that time, cells were incubated with solid S1 at a final concentration of $50 \mu \mathrm{g} / \mathrm{mL}$ for additional $48 \mathrm{~h}$. The cellular uptake and intracellular release of S1 was determined by confocal laser scanning microscopy (CLSM) by tracking rhodamine B associated fluorescence. As shown in Figure 5a, rhodamine B fluorescence (red) was clearly observed in the cellular cytosolic compartment indicating the internalization of nanoparticles, the hydrolysis of the peptidic bonds by the lysosomes and the subsequent delivery of the entrapped dye.

Further studies with S1 were performed to exclude any toxic effect of these nanoparticles. In a typical experiment SK-BR-3 breast cancer cells were treated with S1 for 48h at final concentrations from 6.25 to $100 \mu \mathrm{g} / \mathrm{mL}$. After that time, cell viability assays using WST-1 were carried out. WST-1 reagent can be reduced by mitochondrial enzymes to give a soluble orange product (formazan salt), however this transformation only happens in viable cells. Therefore, after treatment measuring absorbance at $450 \mathrm{~nm}$ against a background control allowed an accurate determination of the number of metabolically active cells in the culture. ${ }^{81}$ Treatment of cells with S1 showed a low toxicity in concentrations up to $100 \mu \mathrm{g} / \mathrm{ml}$ after $48 \mathrm{~h}$ (Figure 5b).

Once studied the intracellular uptake and performance of the gated material S1, SK-BR-3 breast cancer cells were also used to demonstrate cellular internalization of S2 and its capability to delivery loaded doxorubicin. Doxorubicin treatment causes malfunctioning of the mitochondria by non-specific oxidative damage to the outer and the inner membranes, and by 
direct interaction with the mitochondrial DNA or enzymes involved in cell respiration. In addition, doxorubicin inhibits the activity of the nuclear enzyme DNA topoisomerase II, inducing double-stranded DNA breakage. ${ }^{82,83}$ Doxorubicin release from S2 in cells was expected to result in a decrease of cell viability. CLSM images of SK-BR-3 cells incubated with S2 at a concentration of $50 \mu \mathrm{g} / \mathrm{mL}$ for $48 \mathrm{~h}$ displayed a dotted fluorescent pattern, strongly suggesting internalization of nanoparticles and protease-triggered release of doxorubicin (see Figure 5a). In addition, images showed that doxorubicin reached the nuclei producing their fragmentation, thus suggesting cargo release. Furthermore, the cytotoxic effect of S2 was also found through changes in cell morphology and cells detachment, when compared with the untreated control cells (see Figure 5a). Moreover, toxicity of S2 nanoparticles was studied through WST-1 assays. SK-BR-3 breast cancer cells were treated with different concentration of nanoparticles in the 6.25-100 $\mu \mathrm{g} / \mathrm{ml}$ range for $48 \mathrm{~h}$ and the cytotoxic effect of released doxorubicin was evaluated. A clear concentration-dependent decrease of living cells was found when compared to the untreated cells or cells treated with S1. For instance when SK-BR-3 breast cancer cells were treated with S2 at a concentration of $100 \mu \mathrm{g} / \mathrm{ml}$, more of $90 \%$ of cells were effectively killed. 
a)

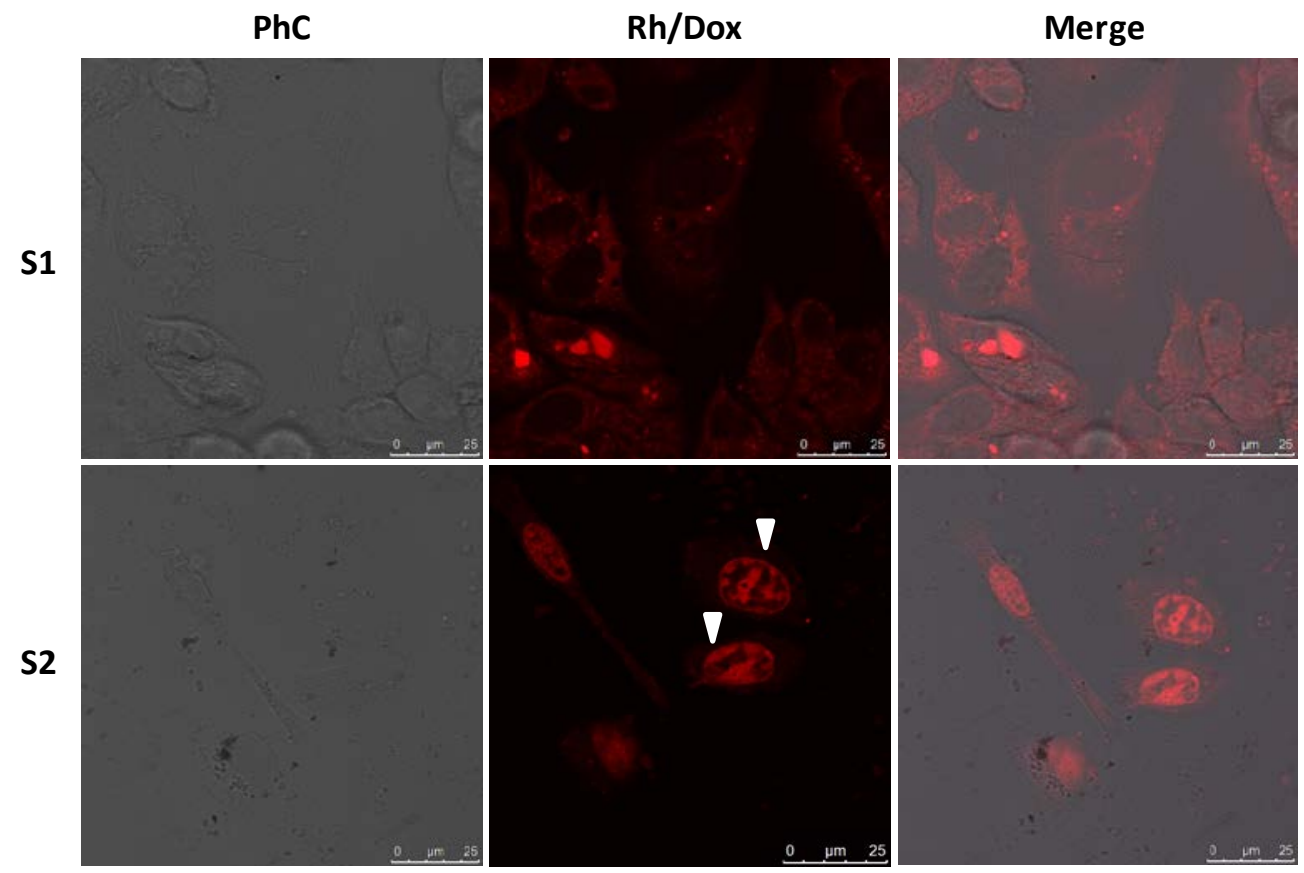

b)

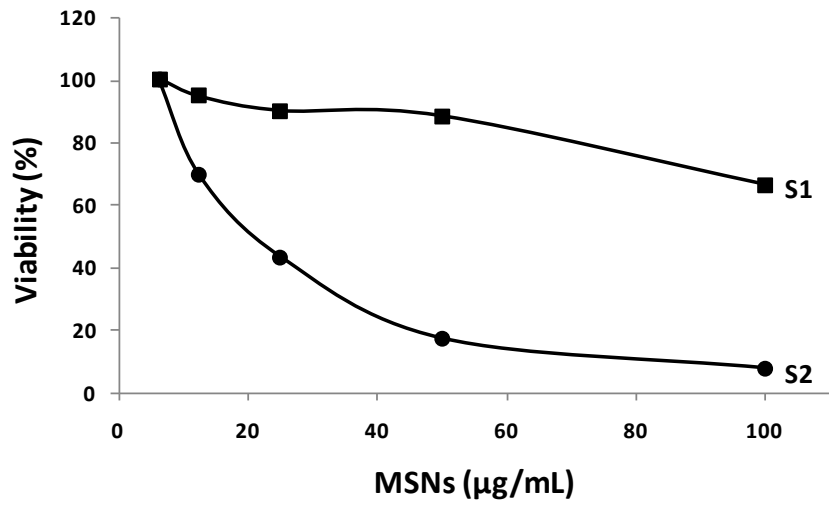

Figure 5. a) Internalization and release of rhodamine B or doxorubicin by $\mathbf{S 1}$ and $\mathbf{S 2}$ nanoparticles, respectively, in SK-BR-3 cells. Cells were treated with $50 \mu \mathrm{g} / \mathrm{ml}$ of S1 or S2 nanoparticles during 48h. Representative phase contrast (PhC), rhodamine B (Rh), doxorubicin (Dox) and combined (Merge) images are shown. White symbols indicate cells apoptotic degradation (nuclei fragmentation). b) Cells were treated with varying concentrations (from 6.25 to $100 \mu \mathrm{g} / \mathrm{mL}$ ) of $\mathbf{S 1}$ or $\mathbf{S} 2$ nanoparticles during $48 \mathrm{~h}$ and viability was determined by WST-1 assay. S2 nanoparticles, loaded with doxorubicin chemotherapeutic drug and gated with PGA, showed a high cytotoxicity, leading to an almost total loss of viability in SK-BR-3 cells.

\section{Conclusions}


In summary, we have described herein a new enzyme-responsive delivery system based in PGA-capped MSNs. In particular, hybrid silica mesoporous nanoparticles loaded with the dye rhodamine B or the drug doxorubicin as cargoes and functionalized with PGA on the external surface were prepared. The solids were characterized using well-known characterization techniques that allowed to found that mesostructure in the final materials $\mathbf{S 1}$ and $\mathbf{S 2}$ was preserved after the loading and functionalization processes. The anchored PGA polymer forms a compact cap that inhibits cargo release effectively. However, in the presence of pronase the peptide bonds are hydrolyzed allowing the release of the entrapped cargo. Typically, S1 and S2 nanoparticles deliver less than $20 \%$ of the cargo at least for $25 \mathrm{~h}$, whereas they are able to reach $90 \%$ of the maximum release of the entrapped guest in ca. $5 \mathrm{~h}$ in the presence of pronase. The performance of solids S1 and S2 in a cellular context was also tested. The uptake of the gated nanoparticles by SK-BR-3 breast cancer cells, their aperture and their ability to deliver the cargo was confirmed. S1 was not toxic, whereas doxorubicin-loaded S2 nanoparticles at a concentration of $100 \mu \mathrm{g} / \mathrm{ml}$ are able to kill efficiently more than $90 \%$ of SK-BR-3 cells. The results reported herein confirms that the use of simple, biocompatible polymers such as PGA is a straightforward way to prepared gated MSNs that remain closed until the presence of enzymes able to hydrolyze peptide bonds.

\section{Corresponding Author}

Prof. Ramón Martínez-Máñez

E-mail: $\underline{\text { rmaez@qim.upv.es }}$

\section{Author Contributions}


The manuscript was written through contributions of all authors. All authors have given approval to the final version of the manuscript. " These authors contributed equally.

\section{ACKNOWLEDGMENT}

A.T. wishes to express her gratitude to the Erasmus mundus (Svagata.eu) financial support. A.U. is grateful to the Ministry of Education, Culture and Sport for her doctoral fellowship. We thank the Spanish Government (Project MAT2015-64139-C4-1-R) and Generalitat Valenciana (Project PROMETEOII/2014/047) for support. They author also thank UPV electron microscopy services for technical support.

\section{ABBREVIATIONS}

APTES, (3-aminopropyl)triethoxysilane; BET, Brunauer-Emmett-Teller; BJH, Barrett-JoynerHalenda; CTAB, n-cetyltrimethylammonium bromide; Dox, doxorubicin; EDC,1ethyl-3-(3dimethylaminopropyl)carbodiimide; MSNs, mesoporous silica nanoparticles; PGA, polyglutamic acid; PhC, phase contrast; Rh, rhodamine B; TEM, transmission electron microscopy; TEOS, tetraethylorthosilicate; WST-1, water soluble tetrazolium salt 1.

\section{REFERENCES}

(1) Slowing, I. I.; Vivero-Escoto, J. L.; Wu, C. W.; Lin, V. S. Y. Mesoporous silica nanoparticles as controlled release drug delivery and gene transfection carriers. Adv. drug deliv. Rev .2008, 60, 1278-1288.

(2) Fedotcheva, T. A.; Olenin, A. Y.; Starostin, K. M.; Lisichkin, G. V.; Shimanovskii, N. L. Prospects for using gold, silver and iron oxide nanoparticles for increasing the efficacy of chemotherapy. Pharm. Chem. J. 2015, 49, 220-230.

(3) Barry, N. P. E.; Sadler, P. J. Challenges for metals in medicine: how nanotechnology may help to shape the future. ACS Nano 2013, 7, 5654-5659.

(4) Marcucci, F.; Corti, A. How to improve exposure of tumor cells to drugs - Promoter drugs increase tumor uptake and penetration of effector drugs. Adv. Drug Deliver. Rev. 2012, 64, 5368. 
(5) Chonn, A.; Cullis, P. R. Recent advances in liposomal drug delivery systems. Curr. Opin. Biotechnol. 1995, 6, 698-708.

(6) Dragojevic, S.; Ryu, J. S.; Raucher, D. Polymer-based prodrugs: improving tumor targeting and the solubility of small molecule drugs in cancer therapy. Molecules 2015, 20, 21750-21769.

(7) Cho, E.; Jung, S. Supramolecular complexation of carbohydrates for the bioavailability enhancement of poorly soluble drugs. Molecules 2015, 20, 19620-19646.

(8) Khan, J.; Rades, T.; Boyd, B. The precipitation behavior of poorly water-soluble drugs with an emphasis on the digestion of lipid based formulations. Pharm. Res. 2016, 33, 548-562.

(9) Rani, V. Nanomedicine and its applications. J. Chem. Pharm. Res. 2015, 7, 216-227.

(10) Nguyen, K. T.; Zhao, Y. Engineered hybrid nanoparticles for on-demand diagnostics and therapeutics. Acc. Chem. Res. 2015, 48, 3016-3025.

(11) Jackman, J. A.; Lee, J.; Cho, N. J. Nanomedicine for infectious disease applications: innovation towards broad-spectrum treatment of viral infections. Small 2016, 12, 1133-1139.

(12) Jager, E.; Giacomelli, F. C. Soft matter assemblies as nanomedicine platforms for cancer chemotherapy: a journey from market products toward novel approaches. Curr. Top. Med. Chem. 2015, 15, 328-344.

(13) Yang, Z.; Kang, S.; Zhou, R. Nanomedicine: de novo design of nanodrugs. Nanoscale 2014, 6, 663-677.

(14) Venugopalarao, G.; Lakshmipathy, R.; Sarada, N. C. Preparation and characterization of cefditorenpivoxil-loaded liposomes for controlled in vitro and in vivo drug release. Int. J. Nanomedicine 2015, 10, 149-157.

(15) Ding, Y.; Sun, D.; Wang, G. L.; Yang, H. G.; Xu H. F.; Chen J. H.; Xie Y.; Wang Z. Q. An efficient PEGylated liposomal nanocarrier containing cell-penetrating peptide and $\mathrm{pH}$-sensitive hydrazone bond for enhancing tumor-targeted drug delivery. Int. J. Nanomedicine 2015, 10, 6199-6214.

(16) Hua, S. Lipid-based nano-delivery systems for skin delivery of drugs and bioactives. Front. Pharmacol. 2015, 6, 219.

(17) Kesharwani, P.; Xie, L.; Banerjee, S.; Mao, G.; Padhye, S.; Sarkar, F. H.; Iyer, A. K. Hyaluronic acid-conjugated polyamidoamine dendrimers for targeted delivery of 3,4difluorobenzylidene curcumin to CD44 overexpressing pancreatic cancer cells. Colloids Surf. B Biointerfaces 2015, 136, 413-423.

(18) Nguyen, H.; Nguyen, N. H.; Tran, N. Q.; Nguyen, C. K. Improved method for preparing cisplatin-dendrimer nanocomplex and its behavior against NCI-H460 lung cancer cell. $J$. Nanosci. Nanotechnol. 2015, 15, 4106-4110.

(19) Lee, S. J.; Jeong, Y. I.; Park, H. K.; Kang, D. H.; Oh, J. S.; Lee, S. G.; Lee, H. C. Enzymeresponsive doxorubicin release from dendrimer nanoparticles for anticancer drug delivery. Int. J. Nanomedicine 2015, 10, 5489-5503.

(20) Alexander, C. M.; Hamner, K. L.; Maye, M. M.; Dabrowiak, J. C. Multifunctional DNAgold nanoparticles for targeted doxorubicin delivery. Bioconjug Chem. 2014, 25, 126112-71.

(21) Unterweger, H.; Tietze, R.; Janko, C.; Zaloga, J.; Lyer, S.; Dürr, S.; Taccardi, N.; Goudouri, O. M.; Hoppe, A.; Eberbeck, D.; Schubert, D. W.; Boccaccini, A. R.; Alexiou, C. Development and characterization of magnetic iron oxide nanoparticles with a cisplatin-bearing polymer coating for targeted drug delivery. Int. J. Nanomedicine 2014, 9, 3659-3676.

(22) Tang, F.; Li, L.; Che, D. Mesoporous silica nanoparticles: synthesis, biocompatibility and drug delivery. Adv. Mater. 2012, 24, 1504-1534. 
(23) Argyo C.; Weiss V.; Bräuchle C.; Bein T. Multifunctional mesoporous silica nanoparticles as universal platform for drug delivery. Chem. Mater. 2014, 26, 435-451.

(24) Vallet-Regí, M.; Rámila, A.; del Real, R. P.; Pérez-Pariente, J. A new property of MCM41: drug delivery system. Chem. Mater. 2001, 13, 308-311.

(25) Aznar, E.; Oroval, M.; Pascual Ll.; Murguía, J. R.; Martínez-Máñez, R.; Sancenón, F. Gated materials for on-command release of guest molecules. Chem. Rev. 2016, 116, 561-718.

(26) Sancenón, F.; Pascual Ll.; Oroval, M.; Aznar, E.; Martínez-Máñez, R. Gated silica mesoporous materials in sensing applications. ChemistryOpen 2015, 4, 418-437.

(27) Aberti, S.; Soler-Illia, G. J. A. A.; Azzaroni, O. Gated supramolecular chemistry in hybrid mesoporous silica nanoarchitectures: controlled delivery and molecular transport in response to chemical, physical and biological stimuli. Chem. Commun. 2015, 51, 6050-6075.

(28) Meng, H.; Xue, M.; Xia, T.; Zhao, Y. L.; Tamanoi, F.; Fraser Stoddart, J.; Zink, J. I.; Nel, A. E. Autonomous in vitro anticancer drug release from mesoporous silica nanoparticles by $\mathrm{pH}-$ sensitive nanovalves. J. Am. Chem. Soc. 2010, 132, 12690-12697.

(29) Cauda, V.; Argyo, C.; Schlossbauer, A.; Bein, T. Controlling the delivery kinetics from colloidal mesoporous silica nanoparticles with ph-sensitive gates. J. Mater. Chem. 2010, 20, 4305-4311.

(30) Angelos, S.; Yang, Y. W.; Patel, K.; Stoddart, J. F.; Zink, J.I. pH-responsive supramolecular nanovalves based on cucurbit[6]uril pseudorotaxanes. Angew. Chem. Int. Ed. 2008, 47, 22222226.

(31) Angelos, S.; Khashab, N. M.; Yang, Y. W.; Trabolsi, A.; Khatib, H. A.; Stoddart, J. F.;Zink, J. I. pH clock-operated mechanized nanoparticles. J. Am. Chem. Soc. 2009, 131, 12912-19214.

(32) Park, C.; Oh, K.; Lee, S. C.; Kim, C. Controlled release of guest molecules from mesoporous silica particles based on a ph-responsive polypseudorotaxane motif. Angew. Chem. Int. Ed. 2007, 46, 1455-1457.

(33) Deng, Z.; Zhen, Z.; Hu, X.; Wu, S.; Xu, Z.; Chu, P. K. Hollow chitosan silica nanospheres as pH-sensitive targeted delivery carriers in breast cancer therapy. Biomaterials 2011, 32, 49764986.

(34) Rossenholm, J. M.; Peuhu, E.; Eriksson, J. E.; Sahlgren, C.; Lindén, M. Targeted intracellular delivery of hydrophobic agents using mesoporous hybrid silica nanoparticles as carrier systems Nano Lett. 2009, 9, 3308-3311.

(35) Huang, X.; Hauptmann, N.; Appelhans, D.; Formanek, P.; Frank, S.; Kaskel, S.; Temme, A.; Voit, B. Synthesis of hetero-polymer functionalized nanocarriers by combining surface-initiated ATRP and RAFT polymerization. Small 2012, 8, 3579-3583.

(36) Chen, L. F.; Di, J. C.; Cao, C. Y.; Zhao, Y.; Ma, Y.; Luo, J.; Wen, Y. Q.; Song, W. G.; Song, Y. L.; Jiang, L. A pH-driven DNA nanoswitch for responsive controlled release. Chem. Commun. 2011, 47, 2850-2852.

(37) Casasús, R.; Marcos, M. D.; Martínez-Mañez, R.; Ros-Lis, J. V.; Soto, J.; Villaescusa, L. A.; Amorós, P.; Beltran, D.; Guillem, C.; Latorre, J. Toward the development of ionically controlled nanoscopic molecular gates. J. Am. Chem. Soc. 2004, 126, 8612-8613.

(38) Mal, N. K.; Fujiwara, M.; Tanaka Y. Photocontrolled reversible release of guest molecules from coumarin-modified mesoporous silica. Nature 2003, 421, 350-353.

(39) He, D. G.; He, X. X.; Wang, K. M.; Cao, J.; Zhao, Y. X. Light-responsive reversible molecule-gated system using thymine-modified mesoporous silica nanoparticles. Langmuir 2012, 28, 4003-4008. 
(40) Ferris, D. P.; Zhao, Y. L.; Khashab, N. M.; Khatib, H. A.; Stoddart, J. F.; Zink, J. I. Lightoperated mechanized nanoparticles. J. Am. Chem. Soc. 2009, 131, 1686-1688.

(41) Liu, R.; Zhang, Y.; Feng, P. Multiresponsive supramolecular nanogated ensembles. J. Am. Chem. Soc. 2009, 131,15128-15129.

(42) Liu, N. G.; Chen, Z.; Dunphy, D. R.; Jiang, Y. B.; Assink, R. A.; Brinker, C. J. Photoresponsive nanocomposite formed by self-assembly of an azobenzene-modified silane. Angew.Chem. Int. Ed. 2003, 42, 1731-1734.

(43) Liu, J.; Bu, W.; Pan, L.; Shi, J. NIR-triggered anticancer drug delivery by upconverting nanoparticles with integrated azobenzene-modified mesoporous silica. Angew.Chem. Int. Ed. 2013, 52, 4375-4379.

(44) Aznar, E.; Casasús, R.; García-Acosta, B.; Marcos, M. D.; Martínez-Máñez, R. Photochemical and chemical two-channel control of functional nanogated hybrid architectures. Adv. Mater. 2007, 19, 2228-2231.

(45) Park, C.; Lee, K.; Kim, C. Photoresponsive cyclodextrin-covered nanocontainers and their sol-gel transition induced by molecular recognition. Angew.Chem. Int. Ed. 2009, 48, 1275-1278.

(46) Fu, Q.; Rao, G. V. R.; Ista, L. K.; Wu, Y.; Andrzejewski, B. P.; Sklar, L. A.; Ward, T. L.; Lopez, G. P. Control of molecular transport through stimuli-responsive ordered mesoporous materials. Adv. Mater. 2003, 15, 1262-1266.

(47) Singh, N.; Karambelkar, A.; Gu, L.; Lin, K.; Miller, J. S.; Chen, C. S.; Sailor, M. J.; Bhatia, S. N. Bioresponsive mesoporous silica nanoparticles for triggered drug release. J. Am. Chem. Soc. 2011, 133, 19582-19585.

(48) Schlossbauer, A.; Warncke, S.; Gramlich, P. M. E.; Kecht, J.; Manetto, A.; Carell, T.; Bein, T. A programmable DNA-based molecular valve for colloidal mesoporous silica. Angew. Chem. Int. Ed. 2010, 49, 4734-4737.

(49) de la Torre, C.; Agostini, A.; Mondragón, L.; Orzaez, M.; Sancenón, F.; Martínez-Máñez, R.; Marcos, M. D.; Amorós, P.; Pérez-Payá, E. Temperature-controlled release by changes in the secondary structure of peptides anchored onto mesoporous silica supports. Chem. Commun. 2014, 50, 3184-3186.

(50) Aznar, E.; Mondragón, L.; Ros-Lis, J. V; Sancenón, F.; Marcos, M. D.; Martínez-Máñez, R.; Soto, J.; Pérez-Payá, E.; Amorós, P. Finely tuned temperature-controlled cargo release using paraffin-capped mesoporous silica nanoparticles. Angew. Chem. Int. Ed. 2011, 50, 11172-11175. (51) Thomas, C. R.; Ferris, D. P.; Lee, J. H.; Choi, E.; Cho, M. H.; Kim, E. S.; Stoddart, J. F.; Shin, J. S.; Cheon, J.; Zink, J. I. Noninvasive remote-controlled release of drug molecules in vitro using magnetic actuation of mechanized nanoparticles. J. Am. Chem. Soc. 2010, 132, 10623-10625.

(52) Paris, J. L.; Cabañas, M. V.; Manzano, M.; Vallet-Regí, M. Polymer-grafted mesoporous silica nanoparticles as ultrasound-responsive drug carriers.ACS Nano 2015, 9, 11023-11033.

(53) Patel, K.; Angelos, S.; Dichtel, W. R.; Coskun, A.; Yang, Y. W.; Zink, J. I.; Stoddart, J. F. Enzyme-responsive snap-top covered silica nanocontainers. J. Am. Chem. Soc. 2008, 130, 23822383.

(54) Schlossbauer, A.; Kecht, J.; Bein, T. Biotin-avidin as a protease-responsive cap system for controlled guest release from colloidal mesoporous silica. Angew. Chem. Int. Ed. 2009, 48, 30923095.

(55) Lu, C. H.; Willner, B.; Willner, I. DNA nanotechnology: from sensing and dna machines to drug-delivery systems. ACS Nano 2013, 7, 8320-8332. 
(56) Climent, E.; Martínez-Máñez, R.; Sancenón, F.; Marcos, M. D.;Soto, J.; Maquieira, A.; Amorós, P. Controlled delivery using oligonucleotide-capped mesoporous silica nanoparticles. Angew.Chem. Int. Ed. Engl. 2010, 49, 7281-7283.

(57) Climent, E.; Mondragón, L.; Martínez-Máñez, R.; Sancenón, F.; Marcos, M. D.; Murguia, J. R.; Amorós, P.; Rurack, K.; Pérez-Payá, E. Selective, highly sensitive, and rapid detection of genomic dna by using gated materials: Mycoplasma detection. Angew. Chem. Int. Ed. 2013, 52, 8938-8942.

(58) Pu, F.; Liu, Z.; Ren, J. S.; Qu, X. G. Nucleic acid-mesoporous silica nanoparticle conjugates for keypad lock security operation. Chem. Commun. 2013, 49, 2305-2307.

(59) Agostini, A.; Mondragón, L.; Pascual, L.; Aznar, E.; Coll, C.; Martínez-Máñez, R.; Sancenón, F.; Soto, J.; Marcos, M.D.; Amorós, P.; Costero, A.M.; Parra, M.; Gil, S. Design of enzyme-mediated controlled release systems based on silica mesoporous supports capped with ester-glycol groups. Langmuir 2012, 28, 14766-14776.

(60) Fernando, I.R.; Ferris, D.P.; Frasconi, M.; Malin, D.; Strekalova, E.; Yilmaz, M.D.; Ambrogio, M.W.; Algaradah, M.M.; Hong, M.P.; Chen, X.; Nassar, M.S.; Botros, Y.Y.; Cryns, V.L.; Stoddart, J.F. Esterase- and pH-responsive poly( $\beta$-aminoester)-capped mesoporous silica nanoparticlesfor drug delivery. Nanoscale 2015, 7, 7178-7183.

(61) Bernardos, A.; Mondragón, L.; Javakhishvili, I.; Mas, N.; de la Torre, C.; Martínez-Máñez, R.; Sancenón, F.; Barat, J. M.; Hvilsted, S.; Orzaez, M.; Pérez-Payá, E.; Amorós, P. Azobenzene polyesters used as gate-like scaffolds in nanoscopic hybrid systems. Chem. Eur. J. 2012, 18, 13068-13078.

(62) Bernardos, A.; Aznar, E.; Marcos, M. D.; Martínez-Máñez, R.; Sancenón, F.; Soto, J.; Barat, J. M.; Amorós, P. Enzyme-responsive controlled release using mesoporous silica supports capped with lactose. Angew. Chem. Int. Ed. 2009, 48, 5884-5887.

(63) Agostini, A.; Mondragón, L.; Bernardos, A.; Martínez-Máñez, R.; Marcos, M. D.; Sancenón, F.; Soto, J.; Costero, A.; Manguán-García, C.; Perona, R.; Moreno-Torres, M.; Aparicio-Sanchis, R.; Murguía, J. R. Targeted cargo delivery in senescent cells using capped mesoporous silica nanoparticles. Angew.Chem. Int. Ed. 2012, 51, 10556-10560.

(64) Park, C.; Kim, H.; Kim, S.; Kim, C. Enzyme Responsive Nanocontainers with cyclodextrin gatekeepers and synergistic effects in release of guests. J. Am. Chem. Soc. 2009, 131, 1661416615.

(65) van Rijt, S.H.; Bölükbas, D.A.; Argyo, C.; Datz, S.; Lindner, M.; Eickelberg, O.; Königshoff, M.; Bein, T.; Meiners, S. Protease-mediated release of chemotherapeutics from mesoporous silica nanoparticles to ex vivo human and mouse lung tumors. ACS Nano 2015, 9, 2377-2389.

(66) de la Torre, C.; Mondragón, L; Coll, C; Sancenón, F; Marcos, M.D.; Martínez-Máñez, R.; Amorós, P.; Pérez-Payá, E.; Orzáez, M. Cathepsin-B induced controlled release from peptidecapped mesoporous silica nanoparticles. Chem. Eur. J. 2014, 20, 15309-15314.

(67) Coll, C.; Mondragón, L.; Martínez-Máñez, R.; Sancenón, F.; Marcos, M. D.; Soto, J.; Amorós, P.; Pérez-Payá, E. Enzyme-mediated controlled release systems by anchoring peptide sequences on mesoporous silica supports. Angew. Chem. Int. Ed. 2011, 50, 2138-2140.

(68) Thornton, P. D.; Heise, A. Highly specific dual enzyme-mediated payload release from peptide-coated silica particles. J. Am. Chem. Soc. 2010, 132, 2024-2028.

(69) Xiao, Y.;Wang,T.; Cao,Y.; Wang,X.; Zhang,Y.; Liu, Y.; Huo, Q. Enzyme and voltage stimuli-responsive controlled release system based on $\beta$-cyclodextrin-capped mesoporous silica nanoparticles. Dalton Trans. 2015, 44, 4355-4361. 
(70) Mas, N.; Agostini, A.; Mondragón, L.; Bernardos, A.; Sancenón, F.; Marcos, M.D.; Martínez-Máñez, R.; Costero, A.M.; Gil, S.; Merino-Sanjuán, M.; Amorós, P.; Orzáez, M.; Pérez-Payá, E. Enzyme-responsive silica mesoporous supports capped with azopyridinium salts for controlled delivery applications. Chem. Eur. J. 2013, 19, 1346-1356.

(71) Zhang, G. L.; Yang, M. L.; Cai, D. Q.; Zheng, K.; Zhang, X.; Wu, L. F.; Wu, Z. Y. Composite of functional mesoporous silica and dna: an enzyme-responsive controlled release drug carrier system. ACS Appl. Mater. Inter. 2014, 6, 8042-8047.

(72) Qian, R.; Ding, L.; Ju, H. Switchable fluorescent imaging of intracellular telomerase activity using telomerase-responsive mesoporous silica nanoparticle. J. Am. Chem. Soc. 2013, 135, $13282-13285$.

(73) Akagi, T.; Higashi, M.; Kaneko, T.; Kida, T.; Akashi, M. Hydrolytic and enzymatic degradation of nanoparticles based on amphiphilic poly(gamma-glutamic acid)-graft-Lphenylalanine copolymers. Biomacromolecules 2006, 7, 297-303.

(74) Eldar-BoocK, A.; Miller, K.; Sanchis, J.; Lupu, R.; Vicent, M. J.; Satchi-Fainaro, R. Integrin-assisted drug delivery of nano-scaled polymer therapeutics bearing paclitaxel. Biomaterials 2011, 32, 3862-3874.

(75) Talelli, M.; Vicent, M. J. Reduction sensitive poly(l-glutamic acid) (PGA)-protein conjugates designed for polymer masked-unmasked protein therapy. Biomacromolecules 2014, $15,4168-4177$.

(76) Manocha, B.; Margaritis, A. Production and characterization of $\gamma$-polyglutamic acid nanoparticles for controlled anticancer drug release. Crit. Rev. Biotechnol. 2008, 28, 83-99.

(77) Coll, C.; Bernardos, A.; Martínez-Máñez, R.; Sancenón, F. Gated silica mesoporous supports for controlled release and signalling applications. Acc. Chem. Res. 2013, 45, 339-349.

(78) Prat, A.; Karginova, O.; Parker, J. S.; Fan, X.; He, X.; Bixby, L.; Harrell, J. C.; Roman, E.; Adamo, B.; Troester, M.; Perou, C. M. Characterization of cell lines derived from breast cancers and normal mammary tissues for the study of the intrinsic molecular subtypes. Breast Cancer Res. Treat. 2013, 142, 237-255.

(79) Swain, S. M.; Baselga, J.; Kim, S. B.; Ro, J.; Semiglazov, V.; Campone, M.; Ciruelos, E.; Ferrero, J. M.; Schneeweiss, A.; Heeson, S.; Clark, E.; Ross, G.; Benyunes, M. C.; Cortés, J. Pertuzumab, trastuzumab, and docetaxel in HER2-positive metastatic breast cancer. N. Engl. J. Med. 2015, 372, 724-734.

(80) Huang, Y.; Fu, P.; Fan, W. Novel targeted therapies to overcome trastuzumab resistance in HER2-overexpressing metastatic breast cancer. Curr. Drug Targets 2013, 14, 889-898.

(81) Ursini, C. L.; Maiello, R.; Ciervo, A.; Fresegna, A. M.; Buresti, G.; Superti, F.; Marchetti, M.; Iavicoli, S.; Cavallo, D. Evaluation of uptake, cytotoxicity and inflammatory effects in respiratory cellsexposed to pristine and $-\mathrm{OH}$ and $-\mathrm{COOH}$ functionalized multi-wall carbon nanotubes. J. Appl. Toxicol. 2016, 36, 394-403.

(82) Patel, S.; Sprung, U.; Keller, B.A.; Heaton, V.J.; Fisher, L. M. Identification of yeast DNA topoisomerase II mutants resistant to the antitumor drug doxorubicin: implications for the mechanisms of doxorubicin action and cytotoxicity. Mol. Pharm. 1997, 52, 658-666.

(83) Lyu, Y. L.; Kerrigan, J. E.; Lin, C. P.; Azarova, A. M.; Tsai, Y. C.; Ban, Y.; Liu, L. F. Topoisomerase IIbeta mediated DNA double-strand breaks: implications in d oxorubicin cardiotoxicity and prevention by dexrazoxane. Cancer Res. 2007, 67, 8839-8846. 
Table of Contents:

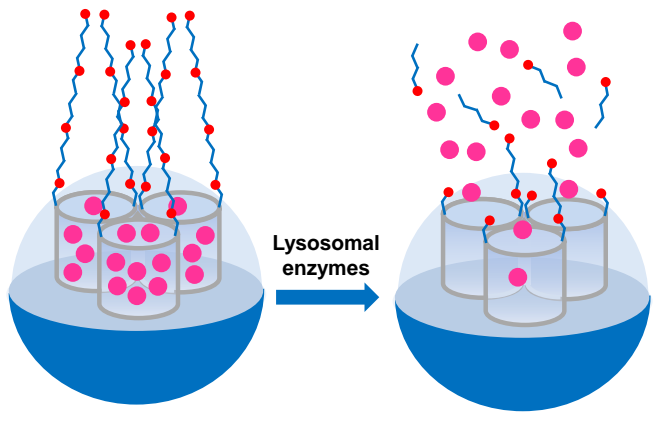

